\title{
PENGARUH PENGELOLAAN PERSEDIAAN BAHAN BAKU TERHADAP EFISIENSI BIAYA PERSEDIAAN DI PT HARMONI MAKMUR SEJAHTERA
}

\author{
Hartono $^{1}$, Indit Andaresta ${ }^{2}$ \\ Fakultas Ilmu Sosial dan Manajemen STIAMI \\ Email : tono1167sh@gmail.com ${ }^{1}$, inditandaresta23@ gmail.com ${ }^{2}$
}

\begin{tabular}{|c|c|}
\hline ARTICLE INFO & ABSTRACT \\
\hline $\begin{array}{l}\text { Article History } \\
\text { Received } 7 \text { November } 2020 \\
\text { Revised } 17 \text { November } 2020 \\
\text { Accepted } 27 \text { November } 2020\end{array}$ & $\begin{array}{l}\text { The purpose of this study is to determine how much the influence of raw } \\
\text { material inventory management to the inventory cost efficiency at PT } \\
\text { Harmoni Makmur Sejahtera. This study uses quantity research methods by } \\
\text { giving questionnaires to } 30 \text { respondents, the calculation and data analysis } \\
\text { conducted by using SPSS version } 25 \text {. From the data proccessing, it was } \\
\text { found a correlation value of } 0.671 \text {, thus it can be concluded that there is a } \\
\text { strong correlation between the variables of raw material stock } \\
\text { management }(X) \text { on the efficiency of inventory costs }(Y) \text {. Result of } R \text { square } \\
(R 2) \text { value of } 0.451 \text { or in the amount of } 45.1 \% \text {, therefore it can be said that } \\
\text { the raw material inventory control variable has an effect of } 45.1 \% \text { on } \\
\text { inventory cost management. The test results show that the t count is } 4.793 \text {. } \\
\text { The } t \text { table value, which is the standard, obtained the } t \text { table value at a } \\
\text { significance level of } 0.05 \text {, which is } 2.480 \text {. The analysis results show the } \\
\text { value of } t \text { count }>\text { t table (4.793> 2.480). This means that Ho is rejected } \\
\text { and HI is accepted, or there is a positive and significant influence between } \\
\text { Raw Material Inventory Management on Inventory Efficiency. }\end{array}$ \\
\hline
\end{tabular}

\section{PENDAHULUAN}

Pembangunan di Indonesia saat ini mengalami laju pertumbuhan yang sangat pesat. Pertumbuhan pembangunan ini membuat penyedia jasa konstruksi semakin menjamur. Menurut data LPJK, saat ini terdaftar sekitar 130.000 Badan Usaha Konstruksi aktif di Indonesia (data pada awal Maret 2020, sumber: lpjk.net). PT Harmoni Makmur Sejahtera merupakan salah satu perusahaan penyedia jasa di bidang konstruksi yang ikut berperan dalam pemenuhan kebutuhan pembangunan infra dan struktur di Indonesia.

Dalam pemenuhan kebutuhan pelanggannya, PT Harmoni Makmur Sejahtera melakukan berbagai cara untuk memberikan pelayanan terbaik mulai dari perencanaan, pengelolaan, pelaksanaan, hingga pengawasan suatu proyek. Manajemen persediaan memegang peranan penting dalam proses pelaksanaan konstruksi karena persediaan merupakan komponen biaya terbesar dalam proses konstruksi. Dengan adanya persediaan mengakibatkan adanya nilai uang yang terkait dalam bentuk persediaan, sehingga bagi perusahaan adanya biaya yang harus ditanggung oleh perusahaan, misalnya sewa gudang, biaya pemesanan, biaya penyimpanan, dan biaya pengaman. Penanaman persediaan yang terlalu besar dibandingkan dengan kebutuhan akan memperbesar penyusutan, besar kemungkinan karena rusak, kualitas menurun, usang, sehingga memperkecil keuntungan yang diperoleh perusahaan. Dan penanaman yang terlalu kecil akan menekan keuntungan juga, karena perusahaan tidak dapat bekerja dengan tingkat produktifitas yang optimal, sehingga akan mempertinggi biaya pengelolaan persediaan.

\section{Rumusan masalah}

Berdasarkan latar belakang masalah diatas, rumusan masalah penilitian ini adalah untuk melihat seberapa besar pengaruh pengelolaan persediaan bahan baku terhadap efisensi biaya Persediaan di PT Harmoni Makmur Sejahtera?

\section{Maksud an tujuan penelitian}

Berdasarkan identifikasi masalah diatas maka yang menjadi tujuan dalam penelitian ini adalah untukmenganalisis seberapa besar pengaruh pengelolaan persediaan bahan baku terhadap efisensi biaya persediaan di PT Harmoni Makmur Sejahtera. 


\section{KAJIAN LITERATUR}

\section{Persediaan}

Menurut Ricky Martono : 2015 Persediaan didefinisikan sebagai semua jenis barang yang dimiliki perusahaan dan digunakan untuk mendukung proses bisnisnya.Pengelolaan persediaan yang baik dapat memberikan nilai tambah berupa service level (pelayanan bagi konsumen),menjaga kualitas barang yang baik, menekan biaya proses, dan menjamin ketersediaan dan waktu pengiriman barang.

Menurut Render dan Heizer (2005), berdasarkan proses manufakturnya persediaan dibagi menjadi empat jenis,yaitu:

1. Persediaan bahan baku (raw material inventory). Adalah persediaan yang dibeli tetapi tidak diproses. Persediaan ini dapat digunakan untuk mendecouple (memisahkan) para pemasok dari proses produksi.

2. Persediaan barang setengah jadi (working in process inventory). Adalah bahan baku atau komponen yang sudah mengalami beberapa perubahan tetapi belum selesai. Adanya work in process disebabkan oleh waktu yang dibutuhkan untuk membuat sebuah produk (disebut siklus waktu). Mengurangi siklus waktu berarti mengurangi persediaan.

3. Persediaan pemeliharaan, perbaikan dan operasi (maintenance, repair, operating, MRO). Pemeliharaan, perbaikan, operasi digunakan untuk menjaga agar permesinan dan proses produksi tetap produktif. MRO tetap ada karena kebutuhan dan waktu pemeliharaan dan perbaikan beberapa peralatan tidak diketahui.

4. Persediaan barang jadi (finished goods inventory). Adalah produk yang sudah selesai dan menunggu pengiriman. Barang jadi bisa saja disimpan karena permintaan pelanggan dimasa depan tidak diketahui.

\section{Pengendalian persediaan}

Pengendalian persediaan merupakan upaya agar persediaan yang disimpan tidak terlalu banyak tapi juga tidak terlalu sedikit, dengan kata lain, teknik pengendalian persediaan digunakan dalam menentukan metode pengawasan terhadap beberapa jenis barang yang sangat strategis, menghitung berapa jumlah optimal tingkat persediaan yang diharuskan, serta kapan saatnya mulai mengadakan pemesanan kembali. Menurut Ristono (2009:4), tujuan dari pengelolaan persediaan adalah

Untuk dapat memenuhi kebutuhan atau permintaan konsumen dengan cepat (memuaskan pelanggan)

Untuk menjaga kontinuitas produksi atau menjaga agar perusahaan tidak mengalami kehabisan persediaan yang mengakibatkan terhentinya proses produksi dikarenakan bahan baku atau bahan penolong menjadi langka dan sulit didapatkan atau kemungkinan supplier terlambat mengirimkan barang yang dipesan

$\square$ Untuk mempertahankan dan bila mungkin meningkatkan penjualan dan laba perusahaan

$\square$ Menjaga agar penyimpanan dapat eplacement tidak besar-besaran karena akan mengakibatkan biaya menjadi besar

\section{METODE PENGELOLAAN PERSEDIAAN}

Menurut Ricky Martono : 2015, terdapat beberapa metode pengelolaan persediaan, diantaranya:

1. Analisis $\mathrm{ABC}$

Analisis $\mathrm{ABC}$ adalah adalah metode pengklasifikasian barang berdasarkan peringkat nilai dari nilai tertinggi hingga terendah, dan dibagi menjadi 3 kelompok besar yang disebut kelompok A, B dan C. Analisis $\mathrm{ABC}$ membagi persediaan yang menjadi tiga kelas berdasarkan besarnya nilai (value) yang dihasilkan oleh persediaan tersebut (Schroeder, 2010). Analisis ABC merupakan aplikasi persediaan yang menggunakan prinsip pareto. Prinsip ini menyatakan bahwa "critical view and trivial many". Prinsip ini mengajarkan untuk memfokuskan pengendalian persediaan kepada jenis persediaan yang bernilai tinggi atau kritikal daripada yang bernilai rendah atau trivial.

\section{Economic Order Quantity (EOQ)}

Model EOQ (Economic Order Quantity) adalah suatu rumusan untuk menentukan kuantitas pesanan yang akan meminimumkan biaya persediaan. Asumsinya adalah

- Jumlah permintaan diketahui, konstan dan idependen

- Waktu tunggu - yakni waktu antara pemesanan dan penerimaan pesanan diketahui dan konstan. 
- Penerimaan persediaan bersifat instan dan selesai seluruhnya. Dengan kata lain, persediaan dari sebuah pesanan datang dalam satu kelompok pada suatu waktu.

- Tidak tersedia diskon kuantitas.

- Biaya variabel hanya biaya unutk menyiapkan atau melakukan pemesanan dan biaya menyimpan persediaan dalam waktu tertentu.

- Kehabisan persediaan dapat sepenuhnya dihindari jika pemesanan dilakukan pada waktu tepat.

\section{Lead Time}

Pengertian lead time menurut Assauri (2008 : 264) adalah lamanya waktu antara mulai dilakukannya pemesanan bahan-bahan sampai dengan kedatangan bahan-bahan yang dipesan tersebut dan diterima di gudang persediaan. Lamanya waktu tersebut tidaklah sama antara satu pesanan dengan pesanan yang lain, tetapi bervariasi. Oleh karena itu untuk suatu pesanan yang dilakukan, lamanya waktu ini harus diperkirakan atau ditaksir, walaupun risiko kesalahan masih tetap ada karena mungkin lebar besar atau kecil. Biasanya persediaan yang diadakan adalah untuk menutupi kebutuhan selama lead time yang telah diperkirakan. Akan tetapi apabila kedatangan bahan tersebut terlambat atau lead time yang terjadi lebih besar daripada yang diperkirakan, maka persediaan yang ditetapkan semula tidak dapat memenuhi kebutuhan penggunaan.

\section{Safety Stock}

Pengertian persediaan pengaman (safety stock) menurut Ristono (2013:7) adalah persediaan yang dilakukan untuk mengantisipasi unsur ketidakpastian permintaan dan penyediaan, apabila persediaan pengaman tidak mampu mengantisipasi ketidak pastian tersebut, akan terjadi kekurangan persediaan (stock out). Sedangkan pengertian menurut Sofjan Assauri (2008 : 263) yaitu persediaan tambahan yang diadakan untuk melindungi atau menjaga kemungkinan terjadi kekurangan bahan (Stock Out).

\section{Titik Pemesanan Ulang (Re- Order Point)}

Menurut Jay Heizer dan Barry Render (2015 : 567), titik pemesanan ulang (Reorder Point) yaitu tingkat persediaan dimana ketika persediaan telah mencapai tingkat itu, pemesanan harus dilakukanKetika jumlah inventory mencapai titik pemesanan kembali (Re-Order Point, ROP), Inventory harus diisi kembali sampai batas tertentu yang dapat mendukung proses operasional perusahaan.

\section{Efisiensi biaya}

Menurut Daryanto SS (2007:181) pengertian efesien dan efesiensi adalah tidak membuang waktu, dana, tenaga sesuai dengan rencana dan tujuan.Sedangkan pengertian efesiensi adalah ketepatan cara (usaha, kerja) dalam menjalankan sesuatu (dengan tidak membuang waktu, tenaga, biaya); kedayagunaan; ketepatgunaan; kesangkilan(Sumber : Kamus Besar Bahasa Indonesia). Efisiensi biaya dalam penelitian ini adalah mengurangi pemborosan-pemborosan dalam proses logistik dan melayani pelanggan dengan kecepatan secepat mungkin, meminimalkan biaya dan memaksimalkan kualitas sehingga dapat meningkatkan daya saing dari suatu perusahaan. Menurut Ricky Martono : 2015, komponen biaya persediaan adalah sebagai berikut

1. Biaya modal/ harga persediaan

Merupakan biaya pengadaan pesediaan sampai perusahaan memperoleh barang tersebut. Terdiri dari biaya pembelian bahan, biaya pajak, biaya bea untuk barang impor, biaya asuransi.

\section{Biaya simpan (Carrying Cost)}

Merupakan biaya penyimpanan material. Terdiri dari biaya penyewaan gudang, gaji pegawai gudang, biaya perawatan tempat penyimpanan,biaya pembelian dan perawatan peralatan penanganan inventory, biaya asuransi Inventory dan biaya kerusakan inventory yang ditanggung perusahaan.

\section{Biaya Pesan (Ordering Cost)}

Terdiri dari gaji karyawan administrasi, biaya telekomunikasi.

4. Biaya Kehabisan Inventory, terdiri dari:

Lost sales cost (Biaya Kehilangan Penjualan), perusahaan akan kehilangan profit atas habisnya inventory

Back Order Cost, berupa biaya atas pemesanan kembali dalam hal penambahan aktivitas pengadaan barang untuk memenuhi keinginan konsumen 
E-ISSN 2621-6442

$\square$ Biaya terkait kapasitas, biasanya terdiri dari biaya rekrut dan mengeluarkan karyawan, biaya lembur, dan biaya pelatihan untuk karyawan baru.

\section{Kerangka teori}

Berdasarkan uraian diatas, maka kerangka teori dinyatakan dalam bentuk bagan sebagai berikut

\begin{tabular}{|l|l|l|}
\hline $\begin{array}{c}\text { Pengelolaan Persediaan Bahan } \\
\text { Baku }\end{array}$ & $\begin{array}{c}\text { Efisiensi Biaya Persediaan } \\
\text { Dimensi: }\end{array}$ \\
1) Analisis ABC & 1) Biaya modal \\
2) Metode EOQ & 2) Biaya simpan \\
3) Lead Time & 3) Biaya Pesan \\
4) Safety Stock & 4) Biaya Kehabisan Persediaan \\
5) Re Order Point & \\
\hline
\end{tabular}

Gambar 1. Pengaruh pengelolaan persediaan bahan baku terhadap efisiensi biaya persediaan di PT Harmoni Makmur Sejahtera

\section{METODE PENELITIAN}

\section{Pendekatan penelitian}

Dalam penelitian ini penulis menggunakan pendekatan kuantitatif. Pendekatan kuantitatif adalah pengukuran data kuantitatif dan statistik objektif melalui perhitungan ilmiah berasal dari sampel orang-orang atau penduduk yang diminta menjawab atas sejumlah pertanyaan tentang survey untuk menentukan frekuensi dan prosentase tanggapan mereka untuk mengukur pengelolaan persediaan bahan baku terhadap efisiensi biaya persediaan di PT Harmoni Makmur Sejahtera. Dimana dalam penelitian ini akan menguji pengaruh pengelolaan persediaan bahan baku terhadap efisiensi biaya persediaan di PT Harmoni Makmur Sejahtera, sehingga dengan metode pendekatan kuantitatif penulis mengharapkan akan mendapatkan data, hasilnya diolah, kemudian dianalisis dan disimpulkan. Dan kesimpulan itu berlaku untuk seluruh populasi, sehingga tujuan penelitian dapat dicapai secara efektif.

\section{Operasionalisasi variabel}

Sesuai dengan judul penelitian yang dipilih penulis yaitu pengaruh pengelolaan persediaan bahan baku terhadap efisiensi biaya persediaan di PT Harmoni Makmur Sejahtera, maka penulis mengelompokan variabel yang digunakan dalam penelitian ini Pengelolaan Persediaan Bahan Baku menjadi variabel independen (X) dan Efisiensi Biaya Persediaan sebagai variabel dependen (Y). Penelitian ini menggunakan variabel dengan indikator seperti berikut :

\begin{tabular}{|c|c|c|c|}
\hline variabel & Dimensi & Indikator & No Item \\
\hline \multirow{8}{*}{$\begin{array}{l}\text { Pengelolaan } \\
\text { Persediaan } \\
\text { (X) }\end{array}$} & \multirow{3}{*}{ Analisis ABC } & a. Urutan Item Inventory & \multirow{3}{*}{$1,2,3$} \\
\hline & & b. Antisipasi kerusakan Inventory & \\
\hline & & c. Menyesuaikan biaya persediaan & \\
\hline & \multirow{3}{*}{ Metode EOQ } & $\begin{array}{l}\text { a. Menentukan jumlah pemesanan } \\
\text { dengan tepat }\end{array}$ & \multirow{3}{*}{$4,5,6$} \\
\hline & & $\begin{array}{l}\text { b. Mempertimbangkan fluktuasi harga } \\
\text { bahan baku }\end{array}$ & \\
\hline & & $\begin{array}{l}\text { c. Memperimbangkan kondisi keuangan } \\
\text { perusahaan }\end{array}$ & \\
\hline & Lead Time & \multirow{2}{*}{$\begin{array}{l}\text { a. Perkiraan waktu kedatangan inventory } \\
\text { b. Memperkiraan faktor keterlambatan } \\
\text { pengiriman } \\
\text { a. Mengantisipasi keterlambatan bahan } \\
\text { baku } \\
\text { b. Mengantisipasi kekurangan material }\end{array}$} & 7,8 \\
\hline & Safety Stock & & 9,10 \\
\hline
\end{tabular}




\begin{tabular}{|c|c|c|c|}
\hline & Re Order Point & \multirow{2}{*}{$\begin{array}{l}\text { a.Menyesuaikan Lead Time pengiriman } \\
\text { dengan penggunaan bahan baku } \\
\text { b. Mengantisipasi kelebihan inventory } \\
\text { a. Biaya Pembelian Bahan } \\
\text { b. Biaya Asuransi }\end{array}$} & 11,12 \\
\hline \multirow{4}{*}{$\begin{array}{l}\text { Efesiensi } \\
\text { Biaya } \\
\text { Persediaan }\end{array}$} & Biaya Modal & & 13,14 \\
\hline & Biaya Simpan & $\begin{array}{l}\text { a. Biaya Sewa Gudang } \\
\text { b. Biaya keamanan } \\
\text { c. Biaya Rusak/ Kehilangan }\end{array}$ & $15,16,17$ \\
\hline & Biaya Pesan & \multirow{2}{*}{$\begin{array}{l}\text { a. Biaya Gaji Karyawan administrasi } \\
\text { b. Biaya telekomunikasi } \\
\text { a. Biaya Pemesanan Berulang } \\
\text { b. Biaya lainnya akibat kehabisan } \\
\text { inventory }\end{array}$} & 18,19 \\
\hline & $\begin{array}{l}\text { Biaya Kehabisan } \\
\text { Inventory }\end{array}$ & & 20,21 \\
\hline
\end{tabular}

\section{Teknik pengumpulan data}

Gambar 2. Indikator Variabel

Dalam penelitian ini penulis berusaha untuk memperoleh beberapa informasi dari pengetahuan yang dapat dijadikan pegangan dalam penelitian yaitu dengan cara studi kepustakaan untuk mempelajari, meneliti, mengkaji, dan menelaah literature-literatur berupa buku, jurnal, bulletin, hasil symposium yang berhubungan dengan penelitian untuk memperoleh bahan-bahan yang akan dijadikan landasan teori.

Selain itu penulis juga menggunakan kuesioner yaitu teknik pengumpulan data yang dilakukan dengan cara memberi seperangkat pertanyaan atau pertanyaan tertulis kepada responden untuk dijawab. Jawaban atas pertanyaan diukur dengan menggunakan skala likert yaitu skala yang mempunyai tingkat gradasi dari yang sangat positif sampai dengan sangat negatif, juga menganalisa data secara kuantitatif.

\section{Populasi dan sampel}

Dalam penelitian ini, penulis memilih seluruh karyawan yang ada di bagian gudang, operasional dan procurement (pengadaan) di PT Harmoni Makmur Sejahtera sebagai sampel dari penelitian ini mengingat karyawan-karyawan ini yang mengurus langsung persediaan bahan baku sebanyak 30 orang.

Dalam penelitian ini penulis mengambil teknik pengambilan sampel Non Probability Sampling yaitu pengambilan sampel jenuh. Menurut Sugiyono (2011:150). Sampling jenuh adalah teknik penentuan sampel bila semua anggota populasi digunakan sebagai sampel. Hal ini sering digunakan jika jumlah populasinya relatif kecil, kurang dari 30 orang.

\section{Teknik analisis data}

1. Uji Validitas

Validitas menunjukkan ukuran yang benar-benar mengukur apa yang akan diukur. Jadi dapat dikatakan semakin tinggi validitas suatu alat test, maka alat test tersebut semakin mengenai pada sasarannya, atau semakin menunjukkan apa yang seharusnya diukur. Salah satu cara untuk menghitung validitas suatu alat test yaitu dengan melihat daya pembeda item (item discriminality). Daya pembeda item adalah metode yang paling tepat digunakan untuk setiap jenis test. Daya pembeda item dalam penalitian ini dilakukan denan cara: "korelasi item-total". yang dalam penelitian ini menggunakan koefisien korelasi Pearson Product Moment dengan langkah-langkah perhitungan sebagai berikut :

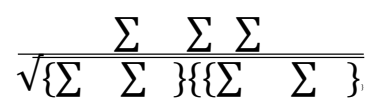

$$
\begin{aligned}
\text { Keterangan : } \quad= & \text { koefisien korelasi pearson } \\
= & \text { Variabel independen } \\
& \text { Variabel dependen } \mathbf{n}= \\
& \text { Banyaknya sampel }
\end{aligned}
$$

2. Uji Reliabilitas 
Reliabilitas merupakan salah satu ciri atau karakter utama intrumen pengukuran yang baik. Kadangkadang reliabilitas disebut juga sebagai keterpercayaan, keterandalan, keajegan, konsistensi, kestabilan, dan sebagainya, namun ide pokok dalam konsep reliabilitas adalah sejauh mana hasil suatu pengukuran dapat dipercaya, artinya sejauh mana skor hasil pengukuran terbebas dari kekeliruan pengukuran (measurement error). Tinggi rendahnya reliabilitas, secara empiris ditunjukkan oleh suatu angka yang disebut koefisien reliabilitas. Walaupun secara teoritis, besarnya koefisien reliabilitas berkisar antara 0,00-1,00.

\section{Analisis Deskriptif}

Dalam penelitian ini pengumpulan data menggunakan kuesioner, karena itu diperlukannya alat ukur untuk menentukan validitas dan reabilitas. Adapun skala penilaian dimualai dari Sangat Tidak Setuju(1), Tidak Setuju (2), Cukup Setuju (3), Setuju (4), Sangat Setuju (5) Kemudian nilai rata-rata tersebut perlu diinterprestasikan atas lima kriteria dengan menggunakan skala interval (Supranto,2000:65) Rumusnya adalah sebagai berikut:

- Jika nilai antara 1.00-1.80 berarti kriteria sangat tidak baik

- Jika nilai antara 1.81-2.60 berarti kriteria kurang baik

- Jika nilai antara 2.61-3.40 berarti kriteria cukup baik

- Jika nilai antara 3.41-4.20 berati kriteria baik

- Jika nilai antara 4.21-5.00 berarti kriteria sangat baik

Selanjutnya, peneliti mengumpulkan, menganaliss dan mentabulasi data menggunakan rumus dari Sanford Labovits yang diterjemahkan oleh Siregar (2000:69) sebagai berikut:

$$
\sum
$$

$$
\begin{aligned}
& \text { Keterangan : } \mathrm{M}=\text { Perolehan Angka Penafsiran } \\
& \mathrm{F} \quad=\text { Frekuensi Jawaban } \\
& \mathrm{X} \quad=\text { Pembobotan (skala nilai) } \\
& \mathrm{n}=\text { Jumlah Sample }
\end{aligned}
$$

\section{Uji Normalitas}

Tujuan uji normalitas adalah untuk mengetahui apakah distribusi sebuah data mengikuti atau mendekati distribusi normal (Situmorang,2010:91). Uji Normalitas dalam penelitian ini dilakukan dengan menggunkan pendekatan kolmogrov-smimov dengan menggunakan tingkat signifikasi 5\%.

5. Uji Hipotesis

a. Uji Korelasi

Uji korelasi juga digunakan untuk mengetahui seberapa besar hubungan yang terjadi antara variabel $\mathrm{X}$ terhadap variabel Y. Pada uji korelasi inisemakin R mendekati 1 maka hubungan yang terjadi semakin kuat, sedangkan semakin nilai $\mathrm{R}$ mendekati 0 maka hubungan yang terjadi semakin lemah. Adapun pedoman yang digunakan adalah sebagai berikut :

\begin{tabular}{|c|c|}
\hline Nilai R & Hasil \\
\hline $\mathbf{0 , 0 0}$ s/d 0,20 & Tidak ada korelasi \\
\hline $\mathbf{0 , 2 1}$ s/d 0,40 & Korelasi lemah \\
\hline $\mathbf{0 , 4 1}$ s/d 0,60 & Korelasi sedang \\
\hline $\mathbf{0 , 6 1}$ s/d 0,80 & Korelasi kuat \\
\hline $\mathbf{0 , 8 1}$ s/d 1,00 & Korelasi sempurna \\
\hline
\end{tabular}

Tabel 3 Pedoman Interprestasi Nilai Korelasi b. Koefisien Determinasi

Koefisien determinasi $\left(\mathrm{R}^{2}\right)$ digunakan untuk mengukur seberapa besar variabel-variabel independen dapat menjelaskan variabel dependen. Koefisien ini menunjukan proporsi variabilitas total pada variabel dependen yang dijelaskan oleh model regresi. Nilai $R^{2}$ berada pada interval $0 \leq R^{2} \leq 1$.

Secara logika dapat diketahui bahwa semakin baik estimasi model dalam menggambarkan data, maka makin dekat nilai R ke nilai 1 (satu). Nilai R2 dapat diperoleh dengan rumus : R2 =(r)2 x 100\%

Keterangan: $\mathrm{R} 2 \quad=$ Koefisien determinasi 


$$
\mathrm{r} \quad=\text { Koefisien korelasi }
$$

c. Uji Regresi Linear Sederhana

Kegunaan regresi dalam penelitian ini salah satunya adalah untuk meramalkan atau memprediksi variabel terikat $(\mathrm{Y})$ apabila variabel bebas $(\mathrm{X})$ diketahui. Regresi linear sederhana dapat dianalisis karena didasari oleh hubungan fungsional atau hubungan sebab akibat (kausal) antara variabel bebas (X) terhadap variabel terikat $(\mathrm{Y})$. Menurut Persamaan regresi linear sederhana dapat dirumuskan sebagai berikut (Alma,2009:97)

$Y=\alpha+b X$

Keterangan :

$\mathrm{Y}$ : Variabel terikat atau response

$\mathrm{X}$ : Variabel bebas atau predictor

$\alpha$ : Nilai Konstanta

b : Koefisien Variabel X

d. Uji Parsial (Uji t)

Uji Parsial digunakan untuk menguji hipotesis dengan membandingkan antara $t_{\text {hitung }}$ dengan $t_{\text {tabel }}$ maka dapat diketahui ada atau tidaknya pengaruh Pengelolaan Persediaan Bahan Baku (X) dengan Efisiensi Biaya Persediaan (Y).

\section{Tempat penelitian}

Lokasi penelitian dilakukan di PT Harmoni Makmur Sejahtera yang berlokasi di Ruko Florencia Blok AA no 11-12, KelapaGading, Jakarta Utara periode Oktober 2019 sd Januari 2020.

\section{HASIL DAN PEMBAHASAN}

\begin{tabular}{|c|c|c|c|c|c|c|c|c|c|c|c|c|}
\hline Indikator & $\mathrm{X} 1$ & $\mathrm{X} 2$ & $\mathrm{X} 3$ & $\mathrm{X} 4$ & $\mathrm{X} 5$ & $\mathrm{X} 6$ & $\mathrm{X} 7$ & $\mathrm{X} 8$ & $\mathrm{X} 9$ & $\mathrm{X} 10$ & $\mathrm{X} 11$ & $\mathrm{X} 12$ \\
\hline Nilai & 4,17 & 4,23 & 4,23 & 4,30 & 3,97 & 4,07 & 4,23 & 4,00 & 4,07 & 4,00 & 4,17 & 4,20 \\
\hline Kriteria & $\mathrm{B}$ & $\mathrm{SB}$ & $\mathrm{SB}$ & $\mathrm{SB}$ & $\mathrm{B}$ & $\mathrm{B}$ & $\mathrm{SB}$ & $\mathrm{B}$ & $\mathrm{B}$ & $\mathrm{B}$ & $\mathrm{B}$ & $\mathrm{B}$ \\
\hline Jumlah & \multicolumn{10}{|c|}{49,63} \\
\hline
\end{tabular}

Tabel 4 Rekapitulasi Variabel Pengelolaan Persediaan Bahan Baku

Dari hasil perhitungan tersebut, maka nilai angka rata-rata penafsiran variabel X (Pengelolaan Persediaan Bahan Baku) sebagai berikut:

$$
=
$$

\begin{tabular}{|c|c|c|c|c|c|c|c|c|c|}
\hline Indikator & Y1 & Y2 & Y3 & Y4 & Y5 & Y6 & Y7 & Y8 & Y9 \\
\hline Nilai & 4,27 & 4,13 & 4,17 & 4,03 & 4,17 & 3,73 & 4,10 & 4,23 & 4,20 \\
\hline Kriteria & SB & B & B & B & B & B & B & SB & B \\
\hline Jumlah & \multicolumn{10}{|c|}{37,03} \\
\hline
\end{tabular}

Tabel 5 Rekapitulasi Variabel Efisiensi Biaya Persediaan

Dari hasil perhitungan tersebut, maka nilai angka rata-rata penafsiran variabel Y (Efisiensi Biaya Persediaan) sebagai berikut:

$$
==4,11(\text { Baik })
$$

\section{HASIL UJI STATISTIK}


a. Uji Normalitas Data

\begin{tabular}{|c|c|c|}
\hline & & Unstandardized Residual \\
\hline $\mathrm{N}$ & & 30 \\
\hline \multirow[t]{2}{*}{ Normal Parameters ${ }^{\mathrm{a}, \mathrm{b}}$} & Mean & 0,0000000 \\
\hline & Std. Deviation & 1,72426681 \\
\hline \multirow[t]{3}{*}{ Most Extreme Differences } & Absolute & 0,121 \\
\hline & Positive & 0,121 \\
\hline & Negative & $-0,120$ \\
\hline Test Statistic & & 0,121 \\
\hline Asymp. Sig. (2-tailed) & & $200^{\mathrm{c}, \mathrm{d}}$ \\
\hline
\end{tabular}

Tabel 6 One-Sample Kolmogorov-Smirnov Test

Berdasarkan uji normalitas K-S/ Kolmogorov-Smirnov di atas (tabel 4.26) diperoleh nilai signifikasi penelitian ini adalah 0,200 . Oleh karena nilai signifikan tersebut $>0,05$, maka dapat disimpulkan bahwa seluruh data dalam penelitian ini berdistribusi normal.

b. Uji Regresi Linear Sederhana

\begin{tabular}{|c|c|c|c|c|c|c|}
\hline \multicolumn{7}{|c|}{ Coefficients $^{\mathrm{a}}$} \\
\hline & \multirow{2}{*}{ Model } & \multicolumn{2}{|c|}{$\begin{array}{c}\text { Unstandardized } \\
\text { Coefficients } \\
\end{array}$} & \multirow{2}{*}{$\begin{array}{c}\begin{array}{c}\text { Standardized } \\
\text { Coefficients }\end{array} \\
\text { Beta }\end{array}$} & \multirow{2}{*}{$\mathrm{t}$} & \multirow{2}{*}{ Sig. } \\
\hline & & B & $\begin{array}{l}\text { Std. } \\
\text { Error }\end{array}$ & & & \\
\hline \multirow[t]{2}{*}{1} & (Constant) & 13,206 & 4,981 & & 2,651 & 0,013 \\
\hline & $\begin{array}{l}\text { Pengelolaan Persediaan } \\
\text { Bahan Baku }\end{array}$ & 0,480 & 0,100 & 0,671 & 4,793 & 0,000 \\
\hline
\end{tabular}

Tabel 7 Hasil Uji Regresi Linear Sederhana

Dari tabel 7 diperoleh persamaan regresi linier sederhana

$$
\begin{aligned}
& Y=\quad+b x \\
& Y=13,206+0,480 X
\end{aligned}
$$

Nilai a $=13,206$ adalah konstanta. Artinya apabila variabel Pengelolaan Persedian Bahan Baku (X) sama dengan nol, maka Efisiensi Biaya Persediaan (Y) sebesar 13,206. Diketahui besarnya koefisien regresi Pengelolaan Persedian Bahan Baku (X) diperoleh 0,480 bernilai positif. Hasil tersebut menunjukkan bahwa setiap terjadi peningkatan Pengelolaan Persedian Bahan Baku (X) sebesar satu satuan maka akan diikuti oleh peningkatan Efisiensi Biaya Persediaan (Y) sebesar 0,480 satuan atau sebaliknya apa bila terjadi penurunan Pengelolaan Persedian Bahan Baku (X) sebesar satu satuan maka akan diikuti oleh penurunan Efisiensi Biaya Persediaan $(\mathrm{Y})$ sebesar 0,480 satuan.

\begin{tabular}{|c|c|c|c|c|c|c|}
\hline & \multicolumn{6}{|c|}{ Coefficients $^{\text {a }}$} \\
\hline & & \multicolumn{2}{|c|}{ Unstandardized } & Standardized & & \\
\hline & Model & \multicolumn{2}{|c|}{ Coefficients } & Coefficients & $\mathrm{t}$ & Sig. \\
\hline & & \multirow[b]{2}{*}{$\mathrm{B}$} & Std. & \multirow[b]{2}{*}{ Beta } & & \\
\hline & & & Error & & & \\
\hline \multirow[t]{5}{*}{1} & (Constant) & 13,206 & 4,981 & & 2,651 & 0,013 \\
\hline & Pengelolaan & 0,480 & 0,100 & 0,671 & 4,793 & 0,000 \\
\hline & Persediaan & & & & & \\
\hline & Bahan Baku & & & & & \\
\hline & a. Dependent & ensi Bi & Persed & & & \\
\hline
\end{tabular}

c. Hasil Uji t

Tabel 8 Hasil Uji t 
Berdasarkan hasil olah data dengan menggunakan SPSS 25 for windows, menunjukkan variabel Pengelolaan Persediaan Bahan Baku (X) mempunyai nilai t hitung sebesar 4,793. Nilai t tabel yang merupakan standar untuk mengambil keputusan pada hipotesis dicari dengan menentukan df. Nilai $\mathrm{df}=\mathrm{n}-\mathrm{k}, \mathrm{n}$ adalah jumlah responden dan $\mathrm{k}$ adalah jumlah semua variabel dalam penelitian ini $(\mathrm{df}=\mathrm{n}-\mathrm{k}=30-2=28)$, diperoleh nilai t tabel pada tingkat signifikansi 0,05 yaitu sebesar 2,480.

Pada penelitian ini terdapat hipotesis:

$\mathrm{H} 0=$ Tidak terdapat pengaruh antara pengelolaan persediaan bahan baku terhadap efiseinsi biaya persediaan

$=$ Terdapat pengaruh signifikan dan positif pengelolaan persediaan bahan baku terhadap efiseinsi biaya persediaan

Hasil analisis menunjukkan nilai $t$ hitung> $t$ tabel $(4,793>2,480)$. Hal ini berarti Ho ditolak dan H1 diterima atau terdapat pengaruh signifikan dan positif pengelolaan persediaan bahan baku terhadap efiseinsi biaya persediaan.

d. Uji Korelasi Parsial Pearson Product Moment

\begin{tabular}{|c|l|r|r|}
\hline & \multicolumn{3}{|c|}{ Correlations } \\
\hline & & Pengelolan Persediaan Bahan Baku & \multicolumn{1}{c|}{ Efisiensi Biaya Persediaan } \\
\hline Pengelolaan & Pearson Correlation & 1 &, $671^{* *}$ \\
\hline Persediaan & Sig. (2-tailed) & & 0,000 \\
\hline & $\mathrm{N}$ & 30 & 30 \\
\hline Efisiensi Biaya & Pearson Correlation & &, $671^{* *}$ \\
\hline Persediaan & Sig. (2-tailed) & 0,000 & 30 \\
\hline & $\mathrm{N}$ & 30 & 30 \\
\hline & $* *$. Correlation is significant at the 0.01 level (2-tailed). \\
\hline
\end{tabular}

Tabel 9 Hasil Uji Korelasi Parsial Pearson Product Moment

Berdasarkan tabel 4.27, dapat diketahui nilai signifikasi adalah 0,000 . Hal itu menunjukkan nilai signifikan $<0,05$ maka dapat disimpulkan bahwa terdapat hubungan antara variabel pengelolaan persediaan bahan baku dengan variabel efisiensi biaya persediaan bahan baku. Adapun nilai pearson correlationnya adalah 0,671 yang berarti pengelolaan persediaan bahan baku terhadap efisiensi biaya persediaan berpengaruh positif dan bersifat kuat.

e. Uji Koefisien Determinasi

\begin{tabular}{|c|c|c|c|c|}
\hline \multicolumn{5}{|c|}{ Model Summary } \\
\hline & \multirow[b]{2}{*}{$\mathrm{R}$} & \multirow[b]{2}{*}{ R Square } & & Std. \\
\hline \multirow{2}{*}{ Model } & & & $\begin{array}{c}\text { Adjusted R } \\
\text { Square }\end{array}$ & $\begin{array}{c}\text { Error of } \\
\text { the }\end{array}$ \\
\hline & & & & Estimate \\
\hline 1 &, $671^{\mathrm{a}}$ & 0,451 & 0,431 & 1,755 \\
\hline \multicolumn{5}{|c|}{ a. Predictors: (Constant), Pengelolaan Persediaan Bahan Baku } \\
\hline \multicolumn{5}{|c|}{ b. Dependent Variable: Efisiensi Biaya Persediaan } \\
\hline
\end{tabular}

Tabel 10 Hasil Uji Koefisien Determinasi

Sedangkan koefisien determinasi $\left(R^{2}\right)$ menunjukkan nilai $R^{2}=0,451$ artinya variabel Pengelolaan Persediaan Bahan Baku (X) dapat menerangkan atau menjelaskan Efisiensi Biaya Persediaan (Y) sebesar $45,1 \%$.

\section{PEMBAHASAN}

Indit Andaresta et.al (pengaruh pengelolaan persediaan bahan baku terhadap efisiensi biaya persediaan di pt harmoni makmur) 
Merujuk pada hasil penelitian yang dilakukan penulis, menunjukan adanya pengaruh yang positif dan siginfikan variabel $\mathrm{X}$ yaitu pengelolaan persediaan bahan baku terhadap variabel $\mathrm{Y}$ yakni efisiensi biaya persediaan di PT Hamoni Makmur Sejahtera. Hal tersebut sesuai dengan hipotesis yang penulis sampaikan pada bab sebelumnya. Selanjutnya, mengacu pada hasil peneitian, berdasarkan hasil uji t terlihat bahwa nilai t-hitung $(4,793)$ lebih besar dari nilai t-tabel $(2,480)$ dan nilai signifikansi lebih kecil dari 0,05 . Hal tersebut menunjukan adanya pengaruh yang signifikan variabel pengelolaan persediaan bahan baku terhadap efisiensi biaya persediaan di PT Hamoni Makmur Sejahtera. Adapun persentase besar pengaruh terlihat pada hasi uji determinasi yang menunjukan niali 0,451 . Artinya pengaruh pengelolaan persediaan bahan baku terhadap efisiensi biaya persediaan di PT Hamoni Makmur Sejahtera sebesar 45,1\%.

\section{KESIMPULAN}

Berdasarkan hasil analisis yang dilakukan, maka peneliti dapat mengambil kesimpulan bahwa terdapat pengaruh pengelolaan persediaan bahan baku terhadap efisiensi biaya persediaan di PT Hamoni Makmur Sejahtera, dimana menunjukan tingkat pengaruh yang kuat (baik) berdasarkan pedoman intepretasi hal ini ditunjukan oleh besarnya nilai koefisien korelasi sebesar 0,671. Adapun besaran pengaruh pengelolaan persediaan bahan baku adalah sebesar $45,1 \%$ terhadap efisiensi biaya persediaan di PT Harmoni Makmur Sejahtera.

\section{REFERENSI}

Agus, Ristono. 2009. Manajemen Persediaan.Yogyakarta : Graha Ilmu

Carter, W.K. 2009. Akutansi Biaya "Cost Accounting". Jakarta : SalembaEmpat.

Drs. R. A. Supriyono, S.U, 2000, Sistem Pengendalian Manajemen, Edisi Pertama, Yogyakarta:

BPFE-Yogyakarta.

Dwiantara, Lukas dan Rumsari Hardi. 2014. Manajemen Logistik. Jakarta : PT. Gramedia Widia Sarana Indonesia.

Ghozali, Imam. 2012. Aplikasi Analisis Multivariate dengan Program IBM SPSS. Yogyakarta:

Universitas Diponegoro

Heizer, Jay dan Barry Render. 2015, Operations Management (Manajemen Operasi), ed.11, Penerjemah: Dwi anoegrah wati S dan Indra Almahdy, Jakarta: Salemba empat.

Herjanto, 2009, Manajemen Operasi dan Produksi, Jakarta : Grasindo Margono, 2004, Metodologi Penelitian Pendidikan, Jakarta :Rineka Cipta.

Martono, Ricky.2015 Manajemen Logistik Terintegrasi, Jakarta : PPm Management, Cetakan I.

Ristono, Agus, 2013, Manajemen Persediaan, Yogyakarta : Graha Ilmu, Schroeder, Goldstein and Rungtusanatham. 2010. Operations Management: Contemporary Concepts and Cases. 5th ed..McGraw-Hill

Sofjan Assauri (2008:264) Manajemen Produksi dan Operasi, Jakarta: Universitas Indonesia

Sugiyono. 2013. Metode Penelitian Kuantitatif, Kualitatif dan R\&D. Bandung: Alfabeta.CV

Supranto J,M. A. (2000). Statistik Teori dan Aplikasi Jilid 1, Edisi Keenem.Jakarta : Erlangga. 